\title{
Crónica y periodismo ético en la era digital. Entrevista con María Teresa Ronderos
}

\author{
Mary Ann Lugo/Michigan State University
}

\begin{abstract}
"Si todos los periodistas trataran a sus entrevistados, y a los protagonistas de sus noticias como si se tratara de ellos mismos o de sus hijos, quizás tendríamos un país menos hirsuto, menos polarizado".
\end{abstract}

María Teresa Ronderos es periodista y directora del programa Open Society for Independent Journalism en la fundación Open Society Foundations. Recibió el premio Simón Bolívar por Guerras recicladas (2015), una obra de reportaje que cuenta la historia del paramilitarismo. Es autora tambien de los libros Retratos del Poder (Planeta, 1997) y Cinco en Humor (Aguilar, 2007). También ha recibido el premio Rey de España y el Lorenzo Natalí de la Unión Europea por su periodismo de investigación y es la primera mujer Colombiana en recibir el premio María Moors Cabot de Columbia University como reconocimiento a su carrera periodística. En la última década, Ronderos fue pionera en crear medios digitales para esclarecer la verdad de los conflictos armados. En colaboración con la Fundación Ideas para la Paz fundó y luego dirigió el portal VerdadAbierta.com para publicar y contextualizar las realidades del conflicto que se revelaban por medio de los procesos de la Ley de Justicia y Paz.

En esta entrevista MTR nos deja saber sus pensamientos sobre la crónica y el periodismo ético en la era digital. En esta época en que los medios compiten por la atención de un público saturado de información, el periodismo de Ronderos ha logrado cautivar el interés del público explicando verdades sin exagerar sentimientos ni protagonizar lo sórdido. El trabajo de María Teresa Ronderos sigue una ética periodística que permanece sólida a medida que los medios se transforman. Esta entrevista nace como parte de una investigación acerca de la empatía en crónicas colombianas del conflicto armado. Ronderos indaga sobre la ética periodística, la responsabilidad del cronista y el desafío que significa escribir sobre "víctimas y victimarios".

MAL ¿Ha cambiado la labor del crónista colombiano desde el auge de los medios digitales? ¿Cómo?

MTR En muchos sentidos la labor del contador de historias periodísticas parece seguir siendo la misma. Las exigencias éticas son las mismas: escarbar e investigar lo que no es evidente, verificar los hechos, darles contexto, ser fiel a las voces consultadas, entre otras. También la necesidad de pensar el lenguaje, para que sea bello, claro y de un amplio registro. Así mismo, aprovechar la naturaleza misma del medio (visual, escrito, sonido) en el cual se esté contando la historia para que nuestra historia llegue más lejos.
Pero vista en acción en la red virtual, la labor se ha ampliado. El periodista dejó de tener el monopolio de los relatos de lo que sucede en el mundo como lo tenía antes de la era digital. Entonces ahora tiene que aprender a vivir en un ecosistema muy distinto. Son miles de ciudadanos con sus propias voces contando lo que pasa. ¿Cómo no aprovechar esa riqueza de pensamientos en nuestras historias? Ahí viene la revolución: contar historias con otros; incluir los relatos de otros en nuestros relatos; descubrir lo que la gente sabe y entretejer sus relatos con los nuestros. Y después de que se sube una historia a la red digital, recién ahí comienza a desarrollarse el relato, en la conversación con otros.

Estas últimas exigencias del mundo digital al periodismo refuerzan también las exigencias éticas y estéticas originales. Si todo el mundo sabe qué pasa en su barrio y lo puede contar, y todo el mundo tiene opiniones sobre muchas cosas que pasan y las puede expresar, ¿qué le queda por aportar al periodismo? Con más razón el contador de historias debe ser riguroso, verficar porque hay muchos ojos expertos encima; y con más razón el contador de historias tiene que ir más allá de lo aparente, investigar, pedirle a la gente que le ayude a atar cabos, a juntar esos pedazos de realidad que suceden y que nadie parece estar atando. Así el periodista aporta a la discusión pública unos hechos documentados y que no siempre están al alcance de la gente; le aporta contexto y fondo al debate.

MAL ¿Qué riesgos asume un periodista hoy que intenta investigar los conflictos armados? ¿Existen formas de censura? ¿Qué obstáculos siguen impidendo que se conozcan verdades sobre los conflictos?

MTR Siempre contar las guerra ha sido riesgoso. Como se ha dicho desde hace años, las batallas también se libran en los medios de información. Y cuando alguien revela algo que deja al desnudo los intereses detrás de la retórica de guerra, eso produce furia entre actores que pueden ser muy violentos y que están armados.

Siempre que hay una guerra hay censura. Si es una guerra internacional, empiezan a jugar las formas de censura explícitas para proteger a las fuerzas propias frente a las enemigas. Si es una guerra interna como la colombiana, hay alinderamientos ideológicos que a veces censuran los relatos consciente o inconscientemente. Por ejemplo, no creo que nadie se haya propuesto expresamente censurar las historias sobre la devastación humana y económica perpetrada por el paramilitarismo en el país, mientras el gobierno de Pastrana negociaba la paz con las Farc en 
el Cagúan. Pero si usted revisa las primeras planas de los principales medios nacionales seguramente va a encontrar muchas relacionadas con el Cagúan y muy pocas con las masacres y el desplazamiento forzado. Se dio así porque los medios tendemos a ser oficialistas, y más aún en tiempos de guerra. Entonces miramos a donde el gobierno nos dijo que miráramos.

Pero lo que más afecta conocer la verdad de lo que está pasando mientras se desarrolla un conflicto violento es la imposibilidad de constatar las conexiones invisibles de la guerra: las intervenciones de gobiernos extranjeros que suelen ser secretas; los motivos económicos de los protagonistas de la guerra. Por ejemplo, encontrar algunos títulos de propiedad de casas y fincas de los jefes paramilitares es una tarea que yo pude hacer sólo cuando ya estaban fuera de combate. Así mismo, saber quiénes manejaron la venta ilegal de armas en Colombia en los años de guerra, sólo se va poder saber quizás ahora que ya está terminando.

MAL ¿Cuál es el valor de un periodismo humano? ¿Cómo puede este periodismo aportar a la construcción de una nación inclusiva?

MTR No entiendo muy bien qué quiere decir por periodismo humano. Pero imagino que se refiere a un periodismo solidario, sensible al sufrimiento humano; que se pone en los zapatos del otro y trata con respeto aún a los delincuentes. No concibo que el periodismo sea otro que así, humano, solidario, sensible. Si todos los periodistas trataran a sus entrevistados, y a los protagonistas de sus noticias como si se trataran de ellos mismos o de sus hijos, quizás tendríamos un país menos hirsuto, menos polarizado.

MAL En una entrevista con el Consejo de Redacción sobre su trabajo con VerdadAbierta.com (https://youtu.be/ PkE99illFMI) subrayó que el periodismo de datos "podía ser incluso más humano que el periodismo convencional". En su entrevista dió el ejemplo del portal Rutas del Conflicto en el cual las cifras se vuelven dinámicas y usables para víctimas que quieren aprender más sobre la historia del conflicto en sus regiones. En la entrevista subrayó que esa es una forma de ser respetuoso con las víctimas. En su opinión ¿Cómo cambian los medios digitales la definición o las estrategias para crear un periodismo humano?

MTR Pues lo bueno del periodismo en la era digital es que tiene que respetar más a sus lectores por obligación porque éstos tienen el poder de responder inmediatamente. Y la gente suele leer más los comentarios de las notas que las notas mismas. También una periodista tiene mayor posibilidad de conversar con su audiencia, de estar más cercana, de escucharla más. Eso, por supuesto, la hace más humana.

MAL En varias entrevistas recientes menciona que "los medios digitales marcan la agenda pública.” ¿Qué ocurre cuando existen temas que son vitales pero no despiertan el interés de los lectores o usuarios en estos medios? ¿Qué herramientas tienen los periodistas en esa situación?

MTR Desde que la gente accede a la mayoría de las noticias vía las redes sociales, es la misma gente la que marca la agenda. Si hay un tema que les duele y les importa, pues hablarán más de él y compartirán más las notas relacionadas a este tema. Pero hay que tener cuidado. Porque hoy hay agentes, muchos de ellos no humanos, sino robots y algoritmos, diseñados para manipular deliberadamente la discusión pública. Entran y buscan peleas, insultan y dan impresiones mentirosas del sentir del público. Y son fuerzas políticas las que han diseñado o les han pagado para ello. Por eso la gente y los periodistas en particular tienen que usar todas las herramientas a su alcance para cerciorarse de que algo que vieron en la redes es verdad antes de compartirlo y opinar airadamente sobre ello. Muchos comentarios muy radicales a veces solo muestran que los robots y los trolls están activos, pero la gente cae en la trampa y se engancha en la radicalización. Un estudio mostró por ejemplo, que en el debate sobre la separación de Cataluña de España y la reacción del gobierno español, una buena parte de los que "opinaron" en redes sociales eran robots, que le daban juego en forma masiva y simultánea a los comentarios más hostiles contra la Unión Europea, para que dieran la sensación de que mucha gente pensaba así. Incluso algunas fotos que indignaron a mucha gente eran falsas.

La principal herramienta de los periodistas para marcar agenda es la colaboración con otros medios, periodistas, organizaciones. Si hay un tema que importa y que es necesario que la gente lo vea, entonces hay que tejer alianzas e informar desde muchas plataformas y muchos ángulos. La competencia por la atención de la gente es muy dura.

MAL En cuanto al periodismo narrativo: ¿Cuáles elementos debería tener un periodismo humano que perfila a víctimas?

MTR Bueno, creo que la repuesta es parecida a la que ya dí antes. Con las víctimas que han sufrido enormemente hay que partir de la base que uno ni siquiera imagina cuánto han sufrido, y por eso mismo hay que tener mucha sensibilidad y solidaridad cuando se les hacen preguntas o se les pide un relato. Hay que escuchar y tener paciencia. Pero eso no quiere decir tratarlas con paternalismo y lástima. Mejor pensar en ellas como seres humanos, iguales a uno, capaces de pensar, actuar, crear. Siempre me negué a presentar a las víctimas solo con la imagen de la que llora y sufre, sólo en esa condición, porque eso niega su humanidad.

MAL ¿Cuáles elementos debería tener un periodismo humano que perfila a victimarios?

MTR Lo mismo, confrontarlos con los hechos de los que son responsables, pero con respeto, con firmeza y no 
traicionar sus relatos (decir realmente lo que nos dijeron en su contexto). No tratarlos para arriba, como unos "machos" que hicieron muchas "hazañas" como a veces ve uno en los medios, con la trivialización de las violaciones a los derechos humanos. Pero tampoco para "abajo", como si uno estuviera en un pedestal mirando a un ser inferior. Es difícil, muy difícil lograr ese balance. Es más bien una lucha con uno mismo.

MAL En tiempos de crisis nacional ¿qué papel desempeñan los cronistas que valoran el periodismo humano?

MTR No estoy muy segura que el término periodismo humano sea el más apropiado. Me gusta más periodismo ético.
Siempre estamos en tiempos de crisis... desde que me conozco. Guerras internas, extrema miseria, desigualdad inaceptable, catástrofes naturales, siempre hay crisis. Entonces el periodismo tiene que ser fiel siempre, haya crisis o no, a sus postulados básicos: contar lo que pasa, verificando los hechos lo mejor posible (y ahora ayudado por las audiencias), dando el contexto, explicando con claridad, curando la información que fluye a rodos por las redes y tratando con decencia a todas sus fuentes. Y también, el periodista tiene que intentar explicar por qué pasa lo que pasa, y como decía el gran periodista Bastenier, luchar contra los propios prejuicios. 